\title{
Functional, Phylogenetic and Host-Geographic Signatures of Labyrinthula spp. Provide for Putative Species Delimitation and a Global-Scale View of Seagrass Wasting Disease
}

\author{
Daniel L. Martin ${ }^{1,2,3} \cdot$ Ylenia Chiari $^{1} \cdot$ Emily Boone $^{4} \cdot$ Timothy D. Sherman $^{1}$. \\ Cliff Ross $^{5}$ • Sandy Wyllie-Echeverria ${ }^{6,7}$ • Joseph K. Gaydos ${ }^{2} \cdot$ Anne A. Boettcher ${ }^{1,8}$
}

Received: 29 September 2015 /Revised: 3 March 2016/Accepted: 6 March 2016 /Published online: 21 April 2016

(C) The Author(s) 2016. This article is published with open access at Springerlink.com

\begin{abstract}
Seagrass meadows form ecologically and economically valuable coastal habitat on every continental margin except the Antarctic, but their areal extent is declining by approximately $2-5 \%$ per year. Seagrass wasting disease is a contributing factor in these declines, with the protist Labyrinthula identified as the etiologic agent. To help elucidate the role of Labyrinthula spp. in global seagrass declines, we surveyed roughly one fourth of all seagrass species to identify Labyrinthula diversity at the strain and/or species level, combining results from culturing methods and two common nuclear DNA markers: the ITS and $18 \mathrm{~S}$ regions of the ribosomal RNA gene complex. After assaying a subset of the resulting isolates (of which 170 were newly sequenced), we produced a cladogenic context for putative seagrasspathogenic versus non-pathogenic Labyrinthula while also defining host and geographic ranges. Assays also suggest that pathogenicity is consistently high (when present; and, even when comparing susceptibility of US East- versus West Coast Zostera marina hosts) while virulence is variable, that
\end{abstract}

Communicated by Kenneth Dunton

Electronic supplementary material The online version of this article (doi:10.1007/s12237-016-0087-z) contains supplementary material, which is available to authorized users.

Daniel L. Martin

DanMartin1547@gmail.com

1 Biology Department, University of South Alabama, Mobile, AL, USA

2 The SeaDoc Society, Karen C. Drayer Wildlife Health Center - Orcas Island Office, University of California at Davis, Eastsound, WA, USA

3 Present address: Prescott, AZ, USA some isolate-host combinations have the potential for host cross-infection, and that several modes of transmission can be effective. Taken together, these data provide additional means for delimiting putative species of Labyrinthula, suggesting at least five seagrass-pathogenic and perhaps ten or more non-pathogenic marine "species", yielding a working definition for ecologists and epidemiologists attempting to reconcile the sundry data related to seagrass wasting disease.

Keywords 18S · SSU $\cdot$ ITS $\cdot$ rDNA $\cdot$ Biogeography Emerging infectious diseases $\cdot$ Opportunist $\cdot$ Parasite . Phylogeography · Plant-pathogen interactions · Virulence . Labyrinthulazosterae $\cdot$ Thalassia testudinum $\cdot$ Zostera marina

\section{Introduction}

The global ocean as we knew it has undergone considerable change due to relatively recent human activity, with some of USA

5 Department of Biology, University of North Florida, Jacksonville, FL, USA

6 Friday Harbor Laboratories, University of Washington, Friday Harbor, WA, USA

7 Center of Marine and Environmental Studies, College of Science and Math, University of the Virgin Islands, Saint Thomas, VI, USA

8 Present address: Embry-Riddle Aeronautical University, Prescott, AZ, USA 
the impacts resulting directly or indirectly from disease (Jackson 2008, 2010). Over a decade ago ocean ecosystems began receiving more attention related to marine epidemics, with reports indicating that not only is disease a common feature capable of shaping marine communities, but that infectious diseases are on the rise (Harvell et al. 1999, 2002; Lafferty et al. 2004; Ward and Lafferty 2004). For example, one of the largest marine epidemics is currently underway, with disease decimating populations of some 20 sea star species along the northeast Pacific (Hewson et al. 2014). Many factors influencing biogeography and global drivers of emerging or re-emerging infectious diseases in both marine and terrestrial systems have anthropogenic origins (e.g., climate change, pollution, acidification, species invasions, overfishing), with climate warming a chief concern among them (Daszak et al. 2000; Dobson and Foufopoulos 2001; Lafferty et al. 2004; Lafferty 2009; Doney et al. 2012; Burge et al. 2014; but also see Wilson 2009; Epstein 2010). Although the drivers have not always been clear for seagrass wasting disease epidemics, seagrasses are long known for their associations with an osmotrophic protist capable of producing this disease: Labyrinthula zosterae (or related Labyrinthula spp.) has been implicated in seagrass die-offs since the 1930s, including one large-scale event (temperate north Atlantic basin) and numerous smaller-scale events in both the northern and southern hemispheres (reviewed in Sullivan et al. 2013).

Labyrinthula spp. belong to the monotypic family Labyrinthulidae (Anderson and Cavalier-Smith 2012), which to date includes mostly marine forms that glide within a communal network of ectoplasm. This shared network earned them a reference as net slime molds, but they have no close relation to the more traditional slime molds (now of the Amoebozoa; Adl et al. 2005), nor to the Fungi. Some eleven species of Labyrinthula are currently recognized, but are difficult to distinguish from one another on the basis of morphology alone (Dick 2001; Bigelow et al. 2005). Significantly, only two epithets, zosterae (Muehlstein et al. 1991) and terrestris (Bigelow et al. 2005), have been applied to sequences from Labyrinthula isolates available in public databases. In contrast, culture-independent studies of environmental 18S rDNA sequences imply that several, and likely many, species of Labyrinthula are typically present in marine ecosystems (e.g., Collado-Mercado et al. 2010). Functional roles for most types are incompletely known, but range from strict saprobes and endophytic parasites (Raghukumar and Damare 2011), to the lesser-known as inhabitants of coral mucus (Ben-Dov et al. 2009) and endosymbionts of an amoebae associated with fish gills (Dyková et al. 2008).

As with many microbes (Heger et al. 2014), progress on understanding the ecology of seagrass wasting disease and Labyrinthula spp. is hindered by a paucity of basic information on species or strain-level genetic diversity, biogeographies, host ranges and specificity, and functional roles within this genus. To date, Labyrinthula associations have been reported from at least 17 seagrass species (Armiger 1964; Vergeer and Hartog 1994). Most often these seagrasses exhibited necrotic lesions that were attributed to Labyrinthula infection, but not all isolates produced disease. For example, Muehlstein et al. (1988) found two morphotypes - one causing disease, one not-present on Zostera marina (eelgrass). Similarly, using DNA sequence evidence, Bockelmann et al. (2012) identified three phylotypes from Z. marina, of which two were genetically dissimilar to the disease producing isolate. Neither of these studies nor the study that provided the original $18 \mathrm{~S}$ rDNA identification of $L$. zosterae (Leander and Porter 2001) paired sequencing directly with pathogenicity testing for their isolates. However, Brakel et al. (2014) did pair geographically based isolate assays and sequencing, but specifically for L. zosterae and only within European eelgrass beds. Thus, at the time of this analysis, the only studies to couple broader assays (across-host-species and large geographic ranges) of isolate pathogenicity with molecular identification are from terrestrial systems, which suggest a hidden diversity of pathogenic and non-pathogenic Labyrinthula for Poaceae hosts (Craven et al. 2005; Douhan et al. 2009). Nevertheless, while the higher classification of Labyrinthulidae has seen progress (Adl et al. 2005, 2007; Tsui et al. 2009; Anderson and CavalierSmith 2012; Beakes et al. 2014), the elucidation of Labyrinthula species has been paltry. Regardless of distinction, outbreaks of seagrass wasting disease have had significant impacts on coastal ecosystems.

Seagrass meadows themselves form ecologically and economically valuable coastal habitat on every continental margin except the Antarctic (Short and Wyllie-Echeverria 1996; Kenworthy et al. 2006; Orth et al. 2006; Duarte et al. 2008; Waycott et al. 2009; Duarte et al. 2013). To help elucidate the genetic diversity, host specificity, geographic range, and pathogenicity of Labyrinthula spp. associated with seagrasses from around the world, we surveyed roughly one quarter of all seagrass species to identify Labyrinthula at the strain and/ or species level using a combination of parasite culturing and phylogenetic analyses. We used two common nuclear DNA markers, the ITS1-5.8S-ITS2 (ITS) and the small subunit (SSU, or 18S) regions of the ribosomal RNA gene complex. A subset of these isolates was assayed for their potential to act as pathogens, producing a molecular-phylogenetic context for putative pathogenicity while also allowing for tests of crossinfection, virulence, and mode of transmission. Geographic distributions and the potential for host specificity of putatively pathogenic and non-pathogenic Labyrinthula phylotypes 
were also examined in a biogeographic context, namely "seagrass bioregions" (Short et al. 2007). Finally, we apply our results to improving the method(s) of Labyrinthula species delimitation in an attempt to further elucidate the complex disease dynamics of this system.

\section{Materials and Methods}

\section{Field Sampling, Culturing, and Pathogenicity Assays}

Seagrass tissue samples (leaf-pieces) were collected opportunistically from around the globe. Samples were placed in plastic bags and kept moist until being placed on culture media that day, or mailed to our laboratory for later processing. In order to recover as many Labyrinthula isolates as possible, leaf surfaces were not sterilized. We used agar-nutrient media following the serum method described by Muehlstein et al. (1988), except that we used an enriched formulation found to produce more robust colonies in the short-term (D. Martin pers. obs.). To $1 \mathrm{~L}$ of $0.45 \mu \mathrm{m}$ filtered seawater adjusted to a salinity of 25, $12 \mathrm{~g}$ agar (USB Noble), $1 \mathrm{~g}$ glucose (Sigma), $0.1 \mathrm{~g}$ each of peptone and yeast extract (Bacto), and $3 \mathrm{mg}$ germanium oxide (Sigma) were added. This solution was autoclaved before cooling to $50{ }^{\circ} \mathrm{C}$ and the addition of $25 \mathrm{~mL}$ of penicillin-streptomycin $\left(10,000\right.$ units $\mathrm{mL}^{-1}$ and $10,000 \mu \mathrm{g} \mathrm{mL}^{-1}$, respectively; MP Biomedicals) and $10 \mathrm{~mL}$ horse serum (GIBCO). Approximately $15 \mathrm{~mL}$ of media was added to individual $10 \mathrm{~cm}$ Petri dishes and allowed to cool before adding samples. Cultures were maintained at room temperature $\left(20-25^{\circ} \mathrm{C}\right)$. For one isolate $(95 \mathrm{w} 1)$ from $Z$. marina, morphological measures ( $n=50$ cells) and descriptions (shape, color in mass) were also recorded from digital images as taken from the leading edge of the primary culture (i.e., the initial colony's growth on agar, emanating $2-3 \mathrm{~cm}$ from fresh leaf tissue), or from downstream processing of later transfers and cell harvesting (for color in mass).

As host damage is a property of the host-parasite interaction, and a microbe is not a pathogen until it causes host damage (sensu stricto; Casadevall and Pirofski 2003), we use the term pathogen more loosely, and primarily to depict the likelihood of the "average" host being damaged through an interaction with a given phylotype of Labyrinthula. Specifically, we defined isolates as pathogenic if visual inspection revealed formation of necrotic lesions in association with inoculation. In this study, we screened 21 different Labyrinthula isolates for potential pathogenicity in 14 separate experiments $(1-14$; but also see two from the literature, 15-16). These encompassed 41 separate treatments, including re-testing of several isolates. Protocols generally followed those of Renn (1936) and Muehlstein et al. (1988), using the same seagrass culture system as Steele et al. (2005), and a "common garden" approach to testing the various isolates and hosts. Briefly, plants were collected as single shoots and acclimated for one week as bare-root cultures while submerged singly within $38 \mathrm{~L}$ tanks of natural seawater $(\approx 25$ $30{ }^{\circ} \mathrm{C}$ and salinity of $\approx 25-30$ ), with a $12: 12 \mathrm{~h}$ light:dark cycle and a saturating irradiance of $200 \mu \mathrm{mol}$ PAR $\mathrm{m}^{-2} \mathrm{~s}^{-1}$. For most experiments, transmission was attempted using autoclaved $0.5 \mathrm{~cm}$ pieces of seagrass inoculated by incubating for up to several days atop rapidly growing Labyrinthula cultures. Inoculated fragments were clipped gently to the middle of second-rank leaves of host plants. Leaves were monitored for seven days for the appearance of lesions. Controls utilized autoclaved but non-inoculated seagrass pieces.

One experiment (6) utilized a single strain/isolate (8b) to address different modes of transmission, including: (a) the aforementioned attached leaf-piece inoculum, (b) loosefloating yet inoculated leaf-pieces, (c) whole-plant inoculum (i.e., a pre-infected/symptomatic plant in loose contact with treatment plant), and (d) $1 \mathrm{~mL}$ of liquid isolate (concentrate of ca $1 \times 10^{6}$ Labyrinthula cells from liquid culture) added to the treatment tank. Negative controls consisted of: (e) normal false-inoculum leaf-piece, attached, and (f) asymptomatic plants with no treatment prescribed.

In each experiment, sample sizes were typically 10 or 30 treatment and control plants per isolate (though fewer were available on several occasions). Most experiments also contained some evaluation of the capacity for cross-infection, with a particular interest in comparing "modern" (i.e., since 2006) Z. marina derived isolates on $Z$. marina hosts from both Pacific and Atlantic populations (the latter presumably having undergone a large-scale Labyrinthula-driven selection event in the 1930s). The capacity to cross-infect hosts of different species and/or families was also evaluated for some isolates. Koch's Postulate was evaluated by randomly selecting symptomatic leaves from several experiments, and then re-isolating or microscopically visualizing Labyrinthula cells from the necrotic lesions.

Virulence (defined herein as the extent of necrotic lesions) was measured in a subset of cross-infection experiments (24 ), and based on the areal percentage of necrotic lesion for a $6 \mathrm{~cm}$ long leaf section centered at the site of inoculation. For these, statistical significance was evaluated by ANOVA and Tukey's post hoc multiple comparisons test (Zar 1984) using SYSTAT v13 $(p<0.05)$.

\section{PCR and Sequencing}

Labyrinthula cells (after multiple transfers, but also from around the time of each experiment) grown in liquid culture (same media, without the agar) were scraped from the lower surfaces of Petri dishes, centrifuged 2 min at $8 \mathrm{G}$, and the supernatant was discarded. To extract genomic DNA from the pellet, $3.2 \mu \mathrm{L}$ ddH20, $1.4 \mu \mathrm{L}$ of $10 \times$ PCR buffer (Applied Biosystems), 
$1.4 \mu \mathrm{L}$ of proteinase $\mathrm{K}$ (20 mg mL $\mathrm{mL}^{-1}$; Fermentas), and $14 \mu \mathrm{L}$ of $10 \%$ TWEEN 80 (Sigma) were added. This solution was subsequently incubated at $65{ }^{\circ} \mathrm{C}$ for $1 \mathrm{~h}$, $94{ }^{\circ} \mathrm{C}$ for $15 \mathrm{~min}$, and then cooled to $4{ }^{\circ} \mathrm{C}$ or frozen until use. Additionally, some samples (for $18 \mathrm{~S}$ sequencing) were extracted using a commercial kit (Invisorb spin tissue mini kit, Stratec Biomedical AG) following the manufacturer's recommendations.

Primers ITS1 (5'-TCCGTAGGTGAACCTGCGG-3') and ITS4 (5'-TCCTCCGCTTATTGATATGC-3') (White et al. 1990), which flank the ITS1-5.8S-ITS2 portion of the eukaryotic rDNA gene region, were used to amplify DNA by PCR in $30 \mu \mathrm{L}$ reaction volumes containing: $\approx 10$ ng of DNA template, $1.5 \mathrm{mM} \mathrm{MgCl}, 50 \mathrm{mM} \mathrm{KCl}$, $15 \mathrm{mM}$ Tris-HCl, $0.1 \mu \mathrm{g} \mu \mathrm{L}^{-1}$ BSA, $200 \mu \mathrm{M}$ each dNTP,

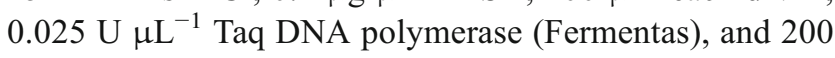
$\mathrm{nM}$ each primer (Integrated DNA Technologies). PCR was conducted using a PTC-100 thermal cycler (MJ Research) with the thermo-profile including 34 cycles of $1 \mathrm{~min}$ at $95{ }^{\circ} \mathrm{C}, 1 \mathrm{~min}$ at $55^{\circ} \mathrm{C}$, and $1 \mathrm{~min}$ at $72{ }^{\circ} \mathrm{C}$, followed by a final $5 \mathrm{~min}$ at $72{ }^{\circ} \mathrm{C}$ (Craven et al. 2005). Aliquots of PCR products were electrophoresed with a commercial molecular weight ladder (Hi-Lo) on $2 \%$ agarose gels stained with ethidium bromide and visualized under U/V light.

PCR amplification of the 18S rDNA region was achieved using the universal primers $18 \mathrm{Sa}\left(5^{\prime}\right.$-AACCT GGTTGATCCTGCCAGT-3') and 18Sb (5'-TGAT CCTTCCGCAGGTTCACCT-3') (Medlin et al. 1988) in $100 \mu \mathrm{L}$ reaction volumes containing: $\approx 10 \mathrm{ng}$ of DNA template in $3 \mathrm{mM} \mathrm{MgCl}_{2}, 50 \mathrm{mM} \mathrm{KCl}, 10 \mathrm{mM}$ Tris- $\mathrm{HCl}, 0.1 \mu \mathrm{g} \mu \mathrm{L}^{-1}$

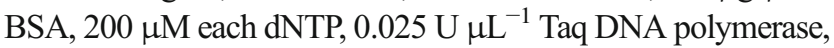
and $200 \mathrm{nM}$ each primer. Thermocycling consisted of one cycle at $94{ }^{\circ} \mathrm{C}$ for $3 \mathrm{~min}$, plus: 40 cycles of $30 \mathrm{~s}$ at $95{ }^{\circ} \mathrm{C}, 1 \mathrm{~min}$ at $52^{\circ} \mathrm{C}$, and $2 \mathrm{~min}$ at $72{ }^{\circ} \mathrm{C}$, followed by a final $10 \mathrm{~min}$ at $72{ }^{\circ} \mathrm{C}$. Visualization was done the same as above, only using $1 \%$ agarose gels. In several cases, when more than one band was observed $(<1000 \mathrm{bp}$ ), distinct bands of the expected size ( $c a$ $1800 \mathrm{bp}$ ) were excised from the gel and purified with a commercial kit (QIAquick) as per manufacturer instructions (QIAGEN), and re-amplified using 28 cycles and the same primers. Individual sequencing runs from these PCR products utilized the $18 \mathrm{~S}$ primers noted above, but also the internal primers $\mathrm{L}$ (5'-CCAACTACGAGCTTTTTAACTG-3') and O (5'AGGGCACCACCAGGAGTGGAG-3') (Apakupakul et al. 1999), and 18Sf2 (5'-CGAATGTAGCGTTTACTGTG-3') and 18Sr3 (5'-GTGCCCTTCCGTCAATTCC-3') (Bergmann et al. 2011), to achieve both forward and reverse coverage.

All PCR products were purified and sequenced in both directions (forward and reverse) via commercial services (Nevada Genomics Center, Reno, Nevada, USA; or, High Throughput Genomics Center, Seattle, Washington, USA). Sequences were edited using Sequencher v4.10.1 (Gene Codes Corp.).

\section{Phylogenetic Analyses}

To increase host-substrate representation, Labyrinthula ITS and $18 \mathrm{~S}$ sequences were also downloaded from GenBank. For both ITS and 18S sequences downloaded from GenBank, only verified (isolated) cultures of previously reported Labyrinthula were used from the NCBI BLASTn database search (i.e., uncultured/environmental sequences were omitted). Sequences were further constrained to those of adequate length, and those with $\geq 50 \%$ query coverage and $\geq 80 \%$ identity to any such "verified" Labyrinthula sequence from GenBank, to help avoid sequences of doubtful origin and provide a more conservative approach. A total of 8 and 25 sequences were therefore downloaded from GenBank for the ITS and $18 \mathrm{~S}$ analyses, respectively.

Subsequent sequence sets $(n=176$ for ITS; $n=35$ for $18 \mathrm{~S}$, including one outgroup) were aligned in MEGA 6 (Tamura et al. 2013) using a CLUSTAL W alignment with the following conditions: $\mathrm{Ts} / \mathrm{Tv}=0$, gap penalty in pairwise alignment of 20 and 50 for the ITS and $18 \mathrm{~S}$ respectively, and a divergence cut off of 60 . The initial $404 \mathrm{bp}$ of the ITS and $957 \mathrm{bp}$ of the $18 \mathrm{~S}$ were processed using Gblocks 0.91b (Castresana 2000) to remove ambiguously aligned base pairs based on the following parameters: minimum number of sequences for a conserved position was 89 and 18 , minimum number of sequences for a flanking position was 149 and 18 , maximum number of contiguous non-conserved positions was 8 and 12, minimum length of a block was 10 , and allowed gap positions was none and half, for the ITS and $18 \mathrm{~S}$ datasets, respectively. The final datasets consisted of a $140 \mathrm{bp}$ alignment for the ITS region, and an 820 bp alignment for the $18 \mathrm{~S}$ region. Finally, the 176 sequences of the ITS dataset were collapsed into 32 haplotypes using DNAcollapser (FaBox online service). All new sequences obtained in this study were deposited in GenBank (accession numbers KU559371-KU559547), with final alignments available as supplementary material (Online Resources 2, 4).

Neighbor joining (NJ) and maximum likelihood (ML) phylogenetic analyses were run separately for each marker. NJ analyses were run in MEGA 6, with 500 bootstrap replicates to estimate branch support values, using $p$-distances, transition/transversion ratio, uniform rate, and pairwise deletion. The best-fitting models of sequence evolution for the ML analyses were determined by the AICc in jModeltest 2.1.6 (Darriba et al. 2012). The best models of evolution were $\mathrm{HKY}+\mathrm{G}$ and $\mathrm{TIM} 2+\mathrm{I}+\mathrm{G}$ for the ITS and $18 \mathrm{~S}$ alignments, respectively. ML analyses were conducted using the online version of PhyML v3 (Guindon et al. 2010) with 1000 bootstrap replicates. Finally, average sequence divergence within and among haplotypes or haplotype groups was calculated as $p$-distances (pairwise deletion option) in MEGA 6. Sequence 
$\%$ identity (percent of same bases at the same positions in an alignment) was derived from sequence divergence $(100-(\%$ sequence divergence)).

\section{Results}

\section{Field Sampling, Culturing, and Pathogenicity Assays}

Field sampling from over 70 sites spanning ten countries, two oceans and both northern and southern hemispheres yielded 172 newly sequenced and/or assayed Labyrinthula isolates from 16 species of seagrass, mangrove detritus, Spartina alterniflora, and a macroalga (including: 168 with new ITS data, though a few were assayed previously and/or have $18 \mathrm{~S}$ counterparts; 2 with only new $18 \mathrm{~S}$ data; and two assayed here but with previously reported ITS data; Table 1, Online Resource 1). Biogeographically, our collection of isolates represents 20 different coastal ocean "ecoregions" (Spalding et al. 2007); or, given that $94 \%$ of these cultures were from seagrasses, five of six "seagrass bioregions" (Short et al. 2007) (Table 1, Online Resource 1). Although we have maintained a number of $L$. zosterae isolates for several years, and have had Thalassia testudinum isolate $8 \mathrm{~b}$ for nearly a decade, many isolates (usually diminutive, non-pathogenic forms) did not survive the few weeks needed for use in both PCR and experimental assays. Many isolates also came from targeted lesions (e.g., Fig. 1a), and all isolates were checked routinely during the culturing process for characteristic ectoplasmic nets and fusiform cells via microscopic examination (e.g., Fig. 1b) - to help ensure that only Labyrinthula were transferred. (Background information/metadata on all isolates can be found in Online Resource 1.)

None of the control plants in our 14 experimental assays showed lesion formation (0\% symptomatic) in association with false-inoculate leaf pieces (Table 2). All induced-lesion tissue subject to re-isolation efforts successfully yielded Labyrinthula cells, thus supporting Koch's postulate. Microscopic examination of necrotic tissue induced by two additional isolates, $8 \mathrm{~b}$ and $209 \mathrm{~b}$ (from T. testudinum and $Z$. marina, respectively), further verified that such lesions were formed in direct association with intracellular infection by Labyrinthula (Fig. 1c and d).

Since environmental conditions varied slightly between experiments, direct comparisons among experiments cannot be made. Instead, we report overall trends. For example, isolate pathogenicity (when it did occur) was generally high on host-species from which they were isolated $(\approx 90-100 \%)$, and usually remained consistent for a given isolate when re-tested over time (e.g., $>1$ year).

Cross-infection challenges embedded within the pathogenicity assays occurred at several levels (see isolate-host versus treated-host origins, Table 2). For among host- species crosses, the T. testudinum derived isolate $8 \mathrm{~b}$ showed a consistent ability (90-100\%; experiments 1 2 ) to infect $Z$. marina. In contrast, different $Z$. marinaderived isolates showed differing abilities to cross-infect, with isolate $209 \mathrm{~b}$ being pathogenic on its natural hostspecies (experiment 8), but unable to cause disease in $T$. testudinum (experiment 9), while isolate $37 \mathrm{~b}$ was able to infect Phylospadix scouleri (experiment 5) - a host that shares the same bioregion (Table 1, Online Resource 1). An isolate from Z. muelleri, 178b3, from Australia (experiment 8) was not able to infect $Z$. marina from the USA, despite having originated from the same host family; however, we were not able to test this isolate on its original host, nor another host from its bioregion.

In a subset of these experiments (2-4; Table 2), virulence was also measured, with no lesions found outside the $6 \mathrm{~cm}$ region used. Experiment 2 showed consistently high pathogenicity, but significantly lower virulence (3.5-14\%) in the across-host-family challenge of isolate $8 \mathrm{~b}$ (from $T$. testudinum) on $Z$. marina relative to the natural host-species challenge of $37 \mathrm{~b}$ on $Z$. marina $(67-79 \% ; p<0.000$; Table 2). Two assays further utilizing virulence measures addressed whether US East Coast $Z$. marina populations might be differentially susceptible to infection relative to US West Coast populations: in experiment 2 , as noted above, no difference was found among test-host origins when using the West Coast Z. marina isolate $37 \mathrm{~b}$, or the non-natural host-species isolate $8 \mathrm{~b}$, though $37 \mathrm{~b}$ produced relatively high levels of virulence (compare below). In contrast, experiment 3 held the treatedhost-plant constant (East Coast Z. marina, from Maryland) while comparing isolates from the two coasts $(1 \mathrm{~b}$, West Coast, Washington; 4b, East Coast, Virginia), revealing significantly different virulence between them (6 and $27 \%$, respectively; $p=0.006$; Table 2 ), even though pathogenicity was $100 \%$ for both. Experiment 4, comparing East Coast isolates $4 \mathrm{~b}$ and $12 \mathrm{~b}$ (also from Virginia) on East Coast Z. marina (from Maryland), also showed significantly different levels of virulence among isolates (22 and $51 \%$, respectively; $p<0.000$ ), but with the same high level of pathogenicity for both (100\%). West Coast isolate 206w also showed consistently high pathogenicity on East Coast plants (experiments 11-13), but virulence was not measured. Taken together, these results generally suggest consistently high pathogenicity but variable virulence among isolates and their hosts, independent of hostgeographic origin. And, cross-infection across both hostspecies and bioregions is possible, at least for one isolate (8b) under laboratory conditions.

Mode of transmission was evaluated briefly in experiment 6 , indicating that all modes tested (infected leaf-drift, infected close-neighbor plant, attached-infected leaf-piece, and waterborne Labyrinthula cells) were successful in the laboratory (Table 2). Sustained direct contact by an infected leaf-piece (treatment "a", clipped onto the test host), 


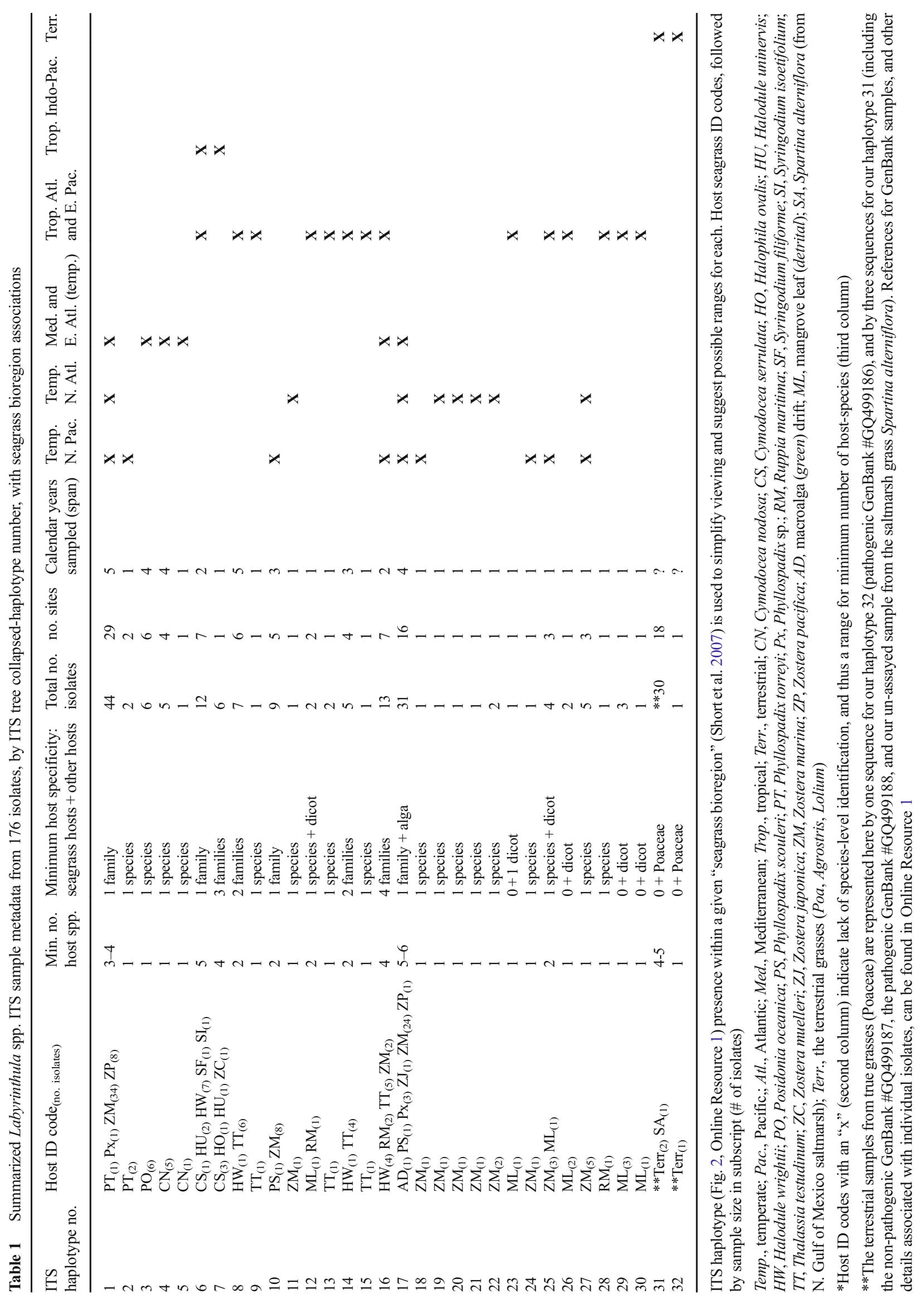






Fig. 1 Putative Labyrinthula lesions, and Labyrinthula cells (in vitro and in vivo). a Symptomatic (necrotic) seagrass tissue (Posidonia oceanica) typical of leaves yielding pathogenic Labyrinthula isolates. Smallest scale divisions $=\mathrm{mm}$. b Phase-contrast image of Labyrinthula $\mathrm{sp}$. isolate $8 \mathrm{~b}$ (from Thalassia testudinum) cells growing across the water-air interface in liquid culture, adhered to a glass coverslip; individual cells (single arrows) can be seen among the reticulate network of ectoplasmic exploratory filopodia (triple arrows) and communal trackways through which

perhaps the most artificial of these situations, appeared the most effective, with $100 \%$ infection success.

\section{Sequencing and Phylogenies}

Phylogenies obtained using the two markers separately recovered similar tree topologies (Figs. 2 and 3) with well supported clades consisting of pathogenic Labyrinthula isolates occurring on seagrasses ("P" clades), pathogenic and nonpathogenic isolates occurring on terrestrial grasses ("T" clades), and a group containing non-pathogenic Labyrinthula isolates occurring on various aquatic vegetation including seagrasses ("N" clades). The 21 individual seagrass isolates assayed herein for pathogenicity represent nine ITS haplotypes (Fig. 2 and Table 1; Online Resource 1). When mapped onto the resulting ITS topology, marine haplotypes were recovered nearly equally among putatively pathogenic ( $\mathrm{P}$ clade, four haplotypes) and non-pathogenic ( $\mathrm{N}$ clade, five haplotypes) forms, with isolates from the Poacea (T clade) containing a mixture of the two (Douhan et al. 2009). Mapping a subset of experimental results onto the smaller yet more host-substrate diverse data set comprising the $18 \mathrm{~S}$ topology showed congruence with this pattern (Fig. 3). Given these clear topological dichotomies relative to function, our results suggest that—for seagrass hosts only—all phylotypes they glide (double arrows). Scale bar $=10 \mu \mathrm{m}$. (c, d) Transmission electron micrographs of Labyrinthula sp. isolate $8 \mathrm{~b}$ and Labyrinthula zosterae isolate $209 \mathrm{~b}$ located within induced seagrass lesions of $T$. testudinum and Z. marina, respectively; cells (in both cross and longitudinal sections; single arrows) are presumed to be from the isolates used to infect the leaves, and the source of the lesions. Scale bars $=2 \mu \mathrm{m}$. Photo credits: D. Martin (a, b), T. Sherman (c), and E. Boone (d)

within these two major clades ( $\mathrm{P}$ and $\mathrm{N}$ ) may fall into the same putative functional groups, pathogenic and non-pathogenic.

\section{Haplotype Diversity, Host Range, and Bioregions}

Labyrinthula spp. metadata (Online Resource 1) on hosts and locations from 176 ITS isolates is summarized in Table 1 according to haplotype numbers presented in Fig. 2. Since $94 \%$ of our marine isolates originated from seagrass hosts, and seagrass disease is a main focus of this study, presence within a given "seagrass bioregion" (sensu Short et al. 2007) was used to suggest possible geographic ranges and climatic regions for each Labyrinthula haplotype. In general, within the putatively pathogenic $(\mathrm{P})$ clade, our data suggest: (1) substrate specificity that is restricted to seagrasses, with no association with detrital mangrove leaves (Figs. 2 and 3; Table 1); (2) isolates from Cymodocea nodosa and Posidonia oceanica are host-species specific, which was observed across sampling sites and years (see clade including haplotypes 3-5, Fig. 2, and/or clades with letter-groups B and C, Figs. 2 and 3; see also Table 1, Online Resource 1); (3) Labyrinthula haplotype geographic ranges are limited within temperate or tropical bioregions, even for non-host-specific types, with some closer relations among tropical haplotypes from the Atlantic and Indo-Pacific than with temperate and tropical types sharing 


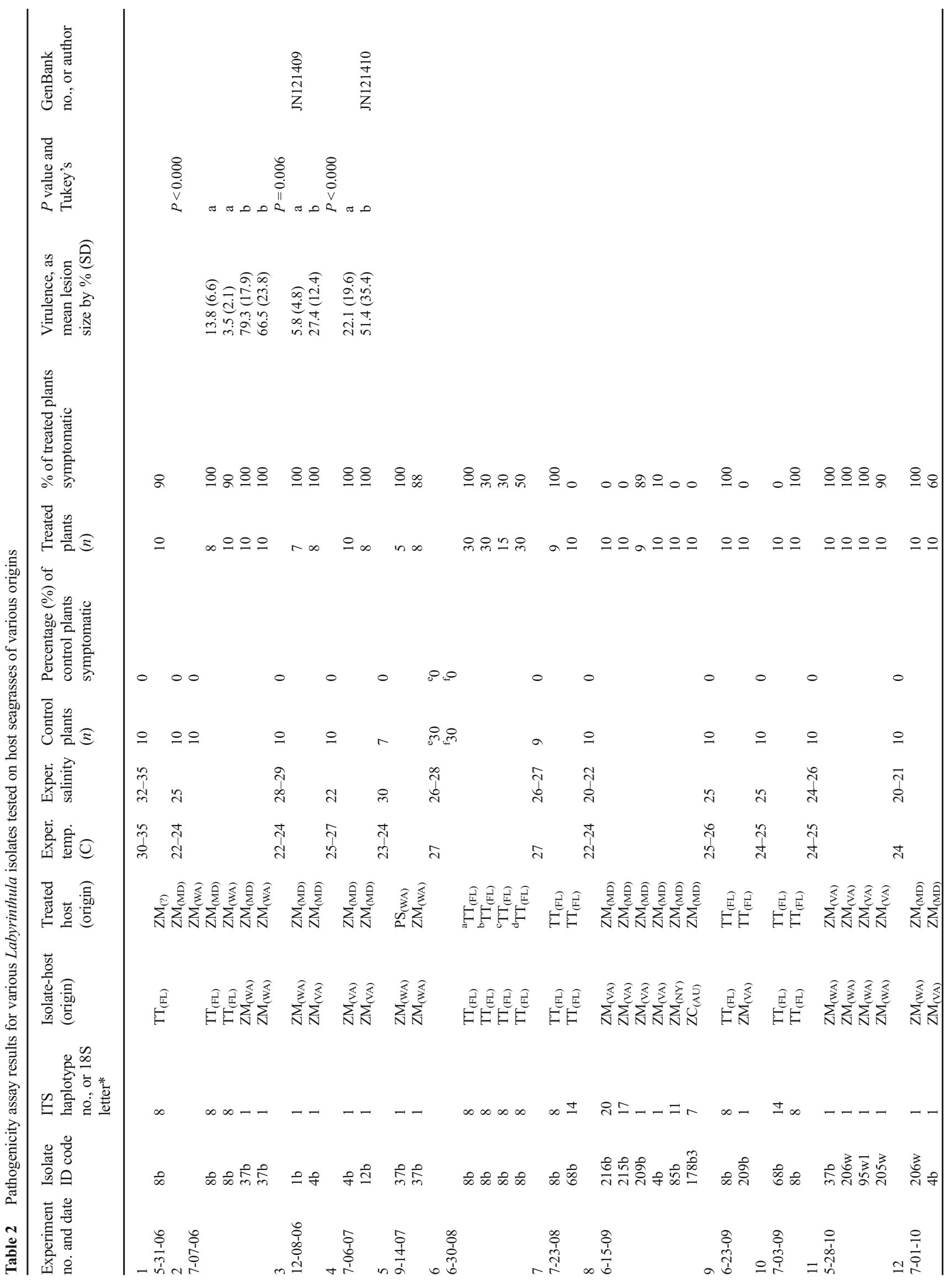




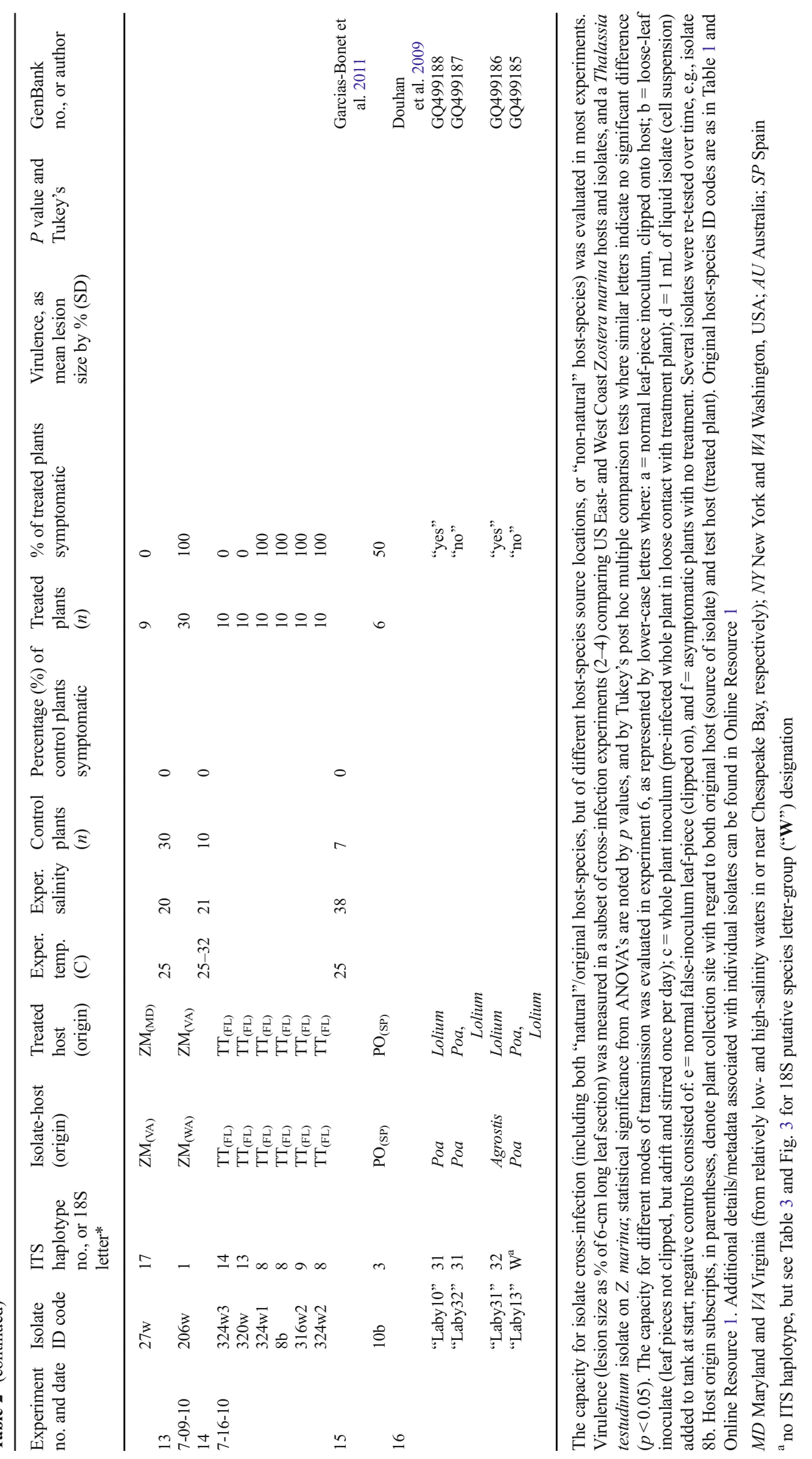






Fig. 2 Labyrinthula spp. phylogeny based on ITS rDNA. The tree is unrooted with neighbor joining $(500 \times)$ and maximum likelihood $(1000 \times)$ bootstrap values, respectively; \#/\#, bootstrap support $<50 \%$; "-", the node was not recovered by one of the phylogenetic analyses. Unless noted otherwise, all sample hosts were seagrasses. Tree 'leaves' represent sequences or similar sequences collapsed into numbered haplotypes (Table 1, Online Resource 1). Large/colored dots, individual isolate assay results, and serve to define the major clades as follows: $P$, putative pathogens on seagrasses (opportunists/biotrophs); $N$, putative

the same host-genus (e.g., for Zostera compare clade including haplotype 1 with clade including haplotypes 6-7, and for Cymodocea compare clade including haplotypes 4-5 with clade including 6-7; Fig. 2 and Table 1); (4) host-generalist haplotypes range modestly to broadly on multiple host seagrasses, i.e., from intra- to inter-familial; and (5) a roughly two-fold lower diversity (as measured nominally by the number of ITS haplotypes derived from the number of sequenced isolates) for the $\mathrm{P}$ clade ( 9 from 84 ) than for the $\mathrm{N}$ clade $(21$ from 88 ) (Table 1). non-pathogens on seagrasses (saprobes/necrotrophs); $T$, from terrestrial and saltmarsh true grasses (possessing both pathogenic and non-pathogenic). Line-encircled clades represent climate-only summaries from "seagrass bioregions" (Short et al. 2007), as in Table 1. *Terrestrial samples from true grasses that represent 30 sequences, for which all isolates tested as pathogenic; as the remaining 29 sequences were nearly identical, just one representative sequence and assay symbol was used herein. Haplotypes further collapsed into putative species by letter-group (bold uppercase within shaded clusters) are defined below and in Table $n$

For the putatively non-pathogenic (N) clade, our ITS data generally suggest: (1) host-ranges are wider than those of the $\mathrm{P}$ clade with several isolates recovered from monocots, dicots, and a macroalga; (2) the saprobe lifestyle to be widespread in this clade (Fig. 3); and (3) a greater diversity of saprobes (as measured nominally by number of individual haplotypes; Table 1) may be recovered from individual host-species (e.g., for the two most extensively sampled hosts: 11-fold more for $Z$. marina, and twofold more for T. testudinum). 


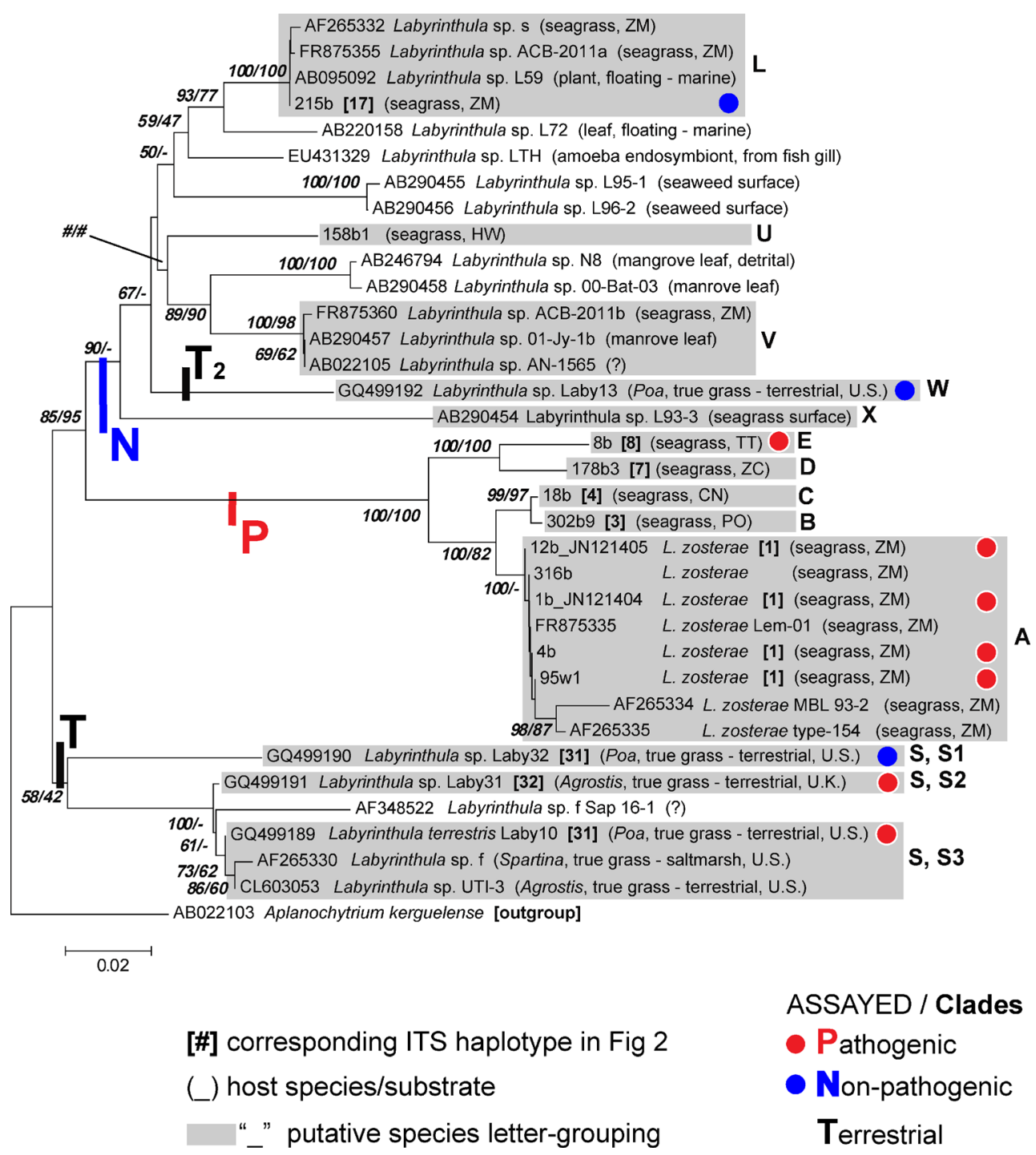

Fig. 3 Labyrinthula spp. phylogeny based on partial 18S rDNA. The tree is rooted, with neighbor joining $(500 \times)$ and maximum likelihood $(1000 \times)$ bootstrap values, respectively; \#/\#, bootstrap support $<42 \%$; “-”, the node was not recovered by one of the phylogenetic analyses. Haplotype number-group (in bold brackets) and host-substrates (in parentheses) are noted to right of isolate/sequence ID codes, with host-substrate codes (mostly seagrasses) as noted in Table 1. Large/colored dots, isolate assay result summaries only (number of individual isolates tested are not

\section{Putative Species Delimitation}

Integrative taxonomy, based on congruence of different data types, has been suggested to be the best approach for improving species discovery and description (Padial et al. 2010). After considering the congruence among the ITS and $18 \mathrm{~S}$ topologies along with what we refer to for convenience as "ecological metadata" (i.e., haplotype host, geographic, and climatic range, along with its putative capacity to function as a pathogen), putative species-level delimitation was determined for ITS haplotypes, or groups of haplotypes, and some seagrass-associated $18 \mathrm{~S}$ sequences. Thus, similar ITS represented by number of dots, as in Fig. 2), and serve to define the major clades as follows: $P$, putative pathogens on seagrasses (e.g., opportunists/ biotrophs); $N$, putative non-pathogens on seagrasses (e.g., saprobes/ necrotrophs); $T$, from terrestrial and saltmarsh true grasses (possessing both pathogenic and non-pathogenic types). Sequences representing putative species by letter-group (bold uppercase following shaded hostsubstrate clusters) are defined below and in Table 3. All GenBank numbers indicate previously reported sequences

sequences assigned to particular haplotype number-groups were further collapsed into putative species letter-groups (in bold uppercase, see Table 3; also see Figs. 2 and 3), with $p$ distance based "\% identity" calculated both within and among-species letter-groups. For example, given the ecological parsing of hosts, regions, and their putative functional roles as pathogens, we are considering ITS P clade haplotypes 1-2 (species letter-group "A"), 3 ("B"), 4-5 ("C"), 8-9 ("E"), and possibly 6-7 ("D"; though haplotype 6 appears in both tropical Atlantic and Indo-Pacific bioregions), as likely representing separate species (see Table 3 and Figs. 2 and 3). The same may be said for some haplotypes or groups of 


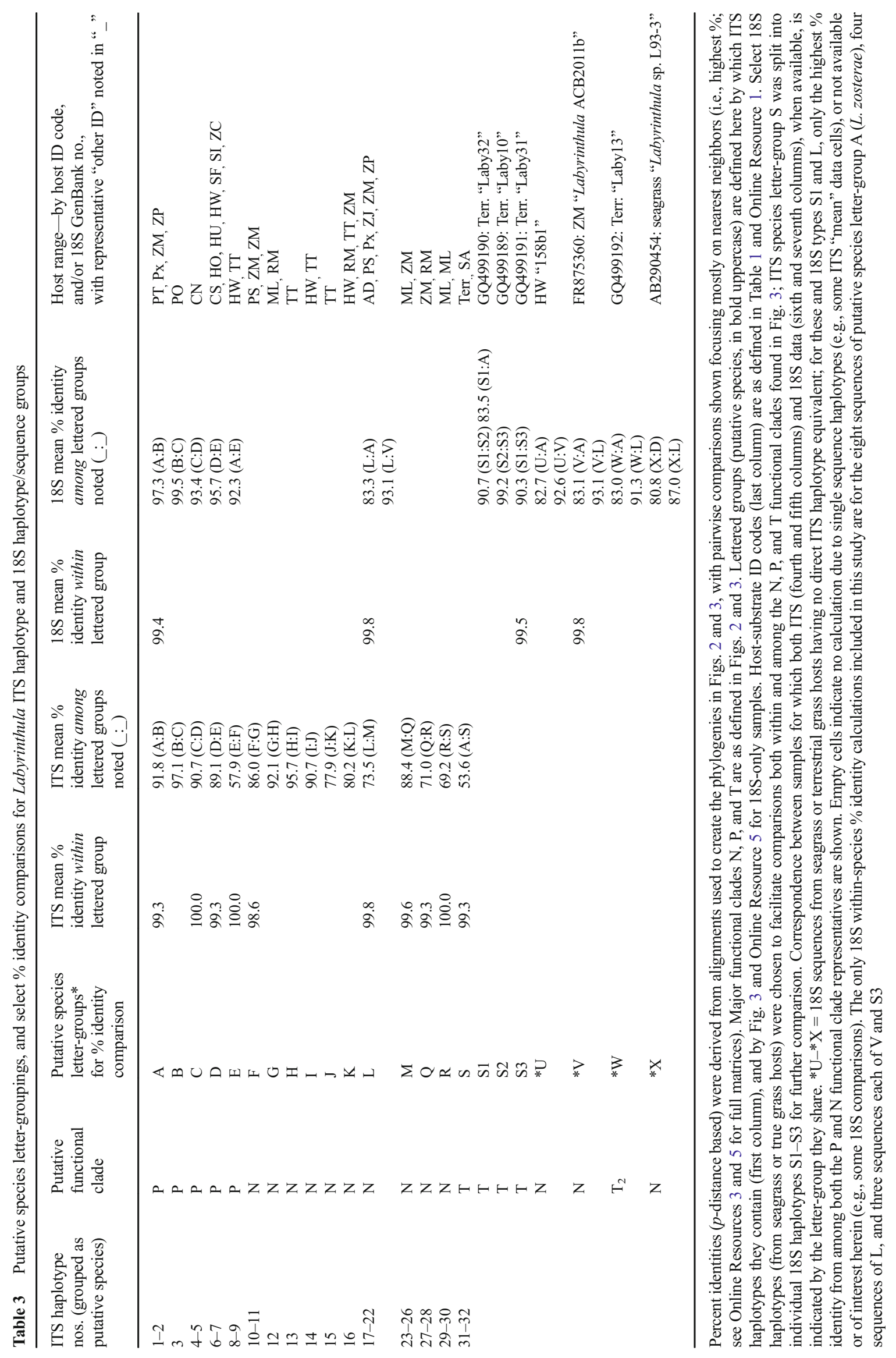


haplotypes in the ITS N clade, although it becomes less clear when host, geographic, and within-group diversity are greater. For example, ITS haplotype number-groups 10-11 (species letter-group "F"), 17-22 ("L") and 23-26 ("M") might comprise individual species, as might 27-28 ("Q") and 29-30 ("R"). The grouping of 12-15 ("G-J") seems less clear, thus they are not combined as a single species here. However, the latter do appear confined to a single seagrass bioregion: the tropical Atlantic and nearby E. Pacific, linked by the Panama Canal. Only N clade haplotypes/putative species 16 ("K"), 23-26 ("M") and 27-28 ("Q") form climatically heterogeneous groups (Fig. 2). Remarkably, among those with only seagrasses as hosts, haplotype 16 (species $\mathrm{K}$ ) appears relatively catholic in having the broadest range of host families (four) and seagrass bioregions (spanning two temperate and one tropical clime), yet is fairly divergent from others within the $\mathrm{N}$ clade. (See Discussion for additional species delimitation rationale.) As parsed, ITS sequence within-species lettergroup mean $\%$ identity ranged from $98.6-100.0 \%$, where $100.0 \%$ is a result of different degenerate-base ambiguity codes being dropped during $p$-distance calculations (though ambiguous base calls may be indicative of intragenomic variability of rDNA cistrons at some positions, the potential level was considered relatively inconsequential here given the average sequence contained just 0.6 ambiguous bases $(0.17 \%$ of all bases), and thus should not affect final sequence groupings). And, among-species/group mean \% identity ranged from 53.6-97.1 \% (Table 3; for full ITS comparison matrix, see Online Resource 3). Furthermore, although representing relatively few sequences, topological congruence and \% identity from the $18 \mathrm{~S}$ phylogeny further support possible separation at the species level, with among-haplotype/group \% identity ranging from $80.0-97.7 \%$ for most isolates having seagrass hosts (Table 3 and Fig. 3). The exception here is for Posidonia oceanica and Cymodocea nodosa derived haplotypes being $99.5 \%$ identical to each other. For L. zosterae, the eight $18 \mathrm{~S}$ sequences used in this analysis yielded a withinspecies \% identity ranging from $98.1-100 \%$ (for full $18 \mathrm{~S}$ comparison matrix, see Online Resource 5). The following morphological data were also collected from our putative $L$. zosterae isolate 95w1 (haplotype 1, species A), for comparison with its formal diagnosis: from $n=50$ cells, mean length $=21.4 \mathrm{~mm}(\mathrm{SD}=2.3$, range $=12.9-25.7)$, mean width $=4.5 \mathrm{~mm}(\mathrm{SD}=0.5$, range $=3.2-6.1)$; cell shape was fusiform (spindle) with hyaline (whitish) color in mass. Several other $18 \mathrm{~S}$ sequence/species letter-groups, including those associated with seagrasses (L, V), were also provided with (when $n>1$ ) pairwise within- and among-species calculations in Table 3.

For additional perspective on sequence divergence above the putative species level, pairwise $18 \mathrm{~S} \%$ identities within and among putative functional clades were also compared, revealing $>90 \%$ within the $\mathrm{P}$ clade, but $<85 \%$ when compared to either the $\mathrm{N}$ or $\mathrm{T}$ clades (Online Resource 5). However pairwise within- and among-group overlap does exist between the $\mathrm{N}$ and T clade $18 \mathrm{~S} \%$ identity measures; likewise, ITS region data fail to show any such \% identity gap among any of the major/functional clades (Online Resources 3, 5).

\section{Discussion}

Using a culture-based survey approach combined with two DNA markers, we present the first data to address both global genetic diversity and functional grouping of seagrass-associated Labyrinthula spp. Pathogenicity assays and phylogenetic analyses provide evidence that putatively pathogenic forms of Labyrinthula on seagrasses belong to a distinct clade, quite apart from the more diverse and putatively non-pathogenic types also found on seagrasses. That this pathogenic group is specific to seagrasses is suggested by the fact that no pathogenic strain was isolated from any of the non-seagrass host-substrates analyzed, and by some apparent host specificity among seagrasses. Such host specificity may further restrict haplotype distribution of pathogens (e.g., this study; Vergeer and Hartog 1994; Bigelow and Olsen 2004; Garcias-Bonet et al. 2011). Our study also suggests that virulence varies among pathogenic isolates, but also depends on their hosts. We further provide evidence indicating that non-pathogenic haplotypes tend to have lower host specificity and broader geographic ranges, traits more characteristic of saprophytes and generalists. Thus, pathogenicity appears to be of a single, cladogenic event for Labyrinthula associated with seagrasses.

When applying the seagrass bioregion concept (Short et al. 2007) to summarize Labyrinthula ITS sequence data (derived from roughly one fourth of all seagrasses, plus some mangrove detritus), it generally appears that while some climate/bioregion-specific haplotypes cross numerous host familial lineages, host-family associated haplotypes tend not to cross seagrass bioregions into different climate zones. In other words, factors related to climate/ regional affiliations appear at least as influential as seagrass familial associations in shaping the genetic diversity seen here. We then used these host- and geography-based results in combination with infection assay- and molecular-based results to propose an additional or enhanced method of species delimitation within the Labyrinthula.

While molecular phylogenetics and systematics have advanced the higher-level resolution of protists considerably over the last decade or so, including the Labyrinthulea (or Labyrinthulomycota) (Anderson and Cavalier-Smith 2012; Beakes et al. 2014), revision at the lower levels has yet to be undertaken for the genus Labyrinthula. Species limits in the genus Labyrinthula have long been considered equivocal 
(Young 1943), and is reflected by three of 13 species considered doubtful, and another eight excluded as synonyms, or considered nomen nudum or of another family, in Dick's (2001) treatment of the group. Many studies (e.g., Olive 1975; Porter 1990; Muehlstein et al. 1991), including the bionomic review by Pokorny (1967) express a major reliance on appearance in vitro including cell length, width, and shape, colony shape in liquid or agar, and color in mass; habitat, cell division, aggregation and zoospore production, speed, nuclear and cytoplasmic condition, ectoplasmic network descriptions, and other observations were also included variously. However, many of these traits commonly overlap among the species Pokorny (1967) discusses, and various isolates of the same putative type (or even subsamples of a given isolate) can vary in nearly all aspects of their appearance depending on age, nutrient sources, and the specific culture medium and conditions used (Watson 1957; Pokorny 1967; Muehlstein et al. 1991; D. Martin pers. obs.). As spore production can be difficult to induce in culture (Watson 1957; Amon and Perkins 1968), and has not been documented for many Labyrinthula, lack of production is also not an ideal trait. More recently, Muehlstein et al. (1991) emphasized the importance of reporting mean cell sizes (not just ranges), standardized culturing conditions (though this may not work well for all types), and host specificity. Ultrastructural investigations using electron microscopy should also enhance descriptions (Muehlstein et al. 1991), though some of these traits also present differently depending on preparation methods. Yet, a comprehensive comparison of "morphological" and "molecular"based approaches herein is not feasible for several reasons: there are no sequence data available for most of the previously described species; many types are reported only from algae, while we confined most of our sampling to seagrasses; and, older reports did not utilize a standard/specific culturing process, or report mean cell sizes (nor do we provide much in the way of morphological data).

As with many protists, we therefore view Labyrinthula as being somewhat cryptic morphologically, and thus an ideal candidate for supplementing its method(s) of species delimitation with molecular data. As both approaches also utilize or require ecological (and other) data, combining numerous methods in future efforts should prove beneficial (Carstens et al. 2013), and is probably vital to any revision of the group — which has been called for (e.g., Porter 1990; Honda et al. 1999). However, as protistan genetic diversity is vastly greater than that within plant, animal or fungal groups, a single genetic marker has not emerged as ideal for approaching species-level investigations, though use of the ITS region has been common (Pawlowski et al. 2012). Consequently, universal molecular criteria for defining cryptic species of protists are nonexistent (Boenigk et al. 2012), and not advocated for (Adl et al. 2007). Yet, any ecological data suggesting limits to population mixing and thus the potential for separately evolving lineages, as well as morphological and functional differences combined with molecular data, should aid in delimiting a "working definition" of such protistan "species" (sensu De Queiroz 2007; Boenigk et al. 2012).

Several previous studies, using less data than we have presented here, have proposed that multiple species of Labyrinthula are associated with seagrasses. ColladoMercado et al. (2010) conducted one of the most detailed reports of genetic diversity within the genus Labyrinthula, utilizing the $18 \mathrm{~S}$ rDNA marker, and concluded that numerous species and possibly more than one genus were detected based on $88 \%$ identity among sequences. Multiple new species in the genus was also suggested in a molecular survey of isolates from a single seagrass host, Z. marina (Bockelmann et al. 2012), as well as in surveys of terrestrial grass isolates (Craven et al. 2005; Douhan et al. 2009), but no specific ways for determining individual species were proposed. In contrast, numerous environmental sequences that grouped with cultivated Aplanochytrium revealed much less variation, with $97.9 \%$ identity across all sequences (Collado-Mercado et al. 2010). Although genetic marker variability can differ markedly among genes, species, and higher taxa, other stramenopile studies utilizing similar markers have shown $p$-distance based $\%$ identities roughly comparable to those reported here. For example, in oomycetes, ITS region identity averaged $71 \%$ among species of different genera and $99.5 \%$ when averaged within species (Robideau et al. 2011).

Our contribution to the delimitation of Labyrinthula species makes use of what we refer to as "ecological metadata" (i.e., isolate-host, geographic, and climatic range, along with its putative capacity to function as a pathogen) in concert with molecular data that utilizes sequence based phylogenies and (mostly) ITS region \% identity calculations, and supplemented with $18 \mathrm{~S}$ region $\%$ identities. The ITS identities are refined with the goal of preventing pairwise intraspecific distances from overlapping with pairwise interspecific distances (the so-called "bar-code gap"; Schoch et al. 2012). In this study, ITS identity ranges from roughly 53-97\% among, and from 98-100\% within, the proposed species groups. Meanwhile, 18S within-species identity measured $98.1-100 \%$ for the eight sequences representing L. zosterae (species A), and $>99 \%$ for the seven sequences used here to comprise the two putative non-pathogenic species $\mathrm{V}$ and $\mathrm{L}$ (also associated with seagrasses, and containing the two new species suggested by Bockelmann et al. 2012; Fig. 3, Online Resource 5). Again, the exception here is for Posidonia oceanica and Cymodocea nodosa derived $18 \mathrm{~S}$ sequences being $99.5 \%$ identical to each other, but considered separate putative species herein (species B, C; Table 3, Figs. 2 and 3). However, they also represent our best cases of host specificity: sampling spanned several years as well as several sites, but no shared haplotypes were found among these hosts (in this study). Both of these hosts 
are also extremely long-lived clonal species (centuries to millennia; Arnaud-Haond et al. 2012) that share a bioregion, suggesting a relatively recent divergence among these haplotypes/putative species. For the only previously described and sequenced marine species, L. zosterae, we also provide basic morphological data (see Results for our isolate 95w1 (haplotype 1, species A)) showing considerable overlap with the diagnosis of $L$. zosterae by Muehlstein et al. (1991). Current L. zosterae strains also demonstrate a similar capacity for pathogenicity, but our sequence data (nearly identical across isolates) shows distribution across several host seagrasses within the same bioregion, whereas the original description considered it exclusive to Zostera marina - although one isolate was reported from necrotic Z. japonica (Muehlstein et al. 1991). Whether sequence based descriptions reveal strong associations between $L$. zosterae and algae, and thus possible habitat overlap with previously described types, remains to be revealed.

As a conservative marker relative to the ITS region (Anne 2006), 18 S region among-species \% identity ranges relatively broadly (from 80-98 \%) herein for most seagrass-associated types, further suggesting a new genus may be needed (e.g., Collado-Mercado et al. 2010). Although a more detailed treatment is beyond the scope of this study, the degree of phylogenetic divergence at the level of the putative functional clades suggested here $(\mathrm{P}, \mathrm{N}$, and $\mathrm{T})$ is further revealed in a comparison of $18 \mathrm{~S} \%$ identity, showing no pairwise overlap for within-group and among-group $\%$ identities when comparing the $\mathrm{P}$ clade ( $>90 \%$ within) to either the $\mathrm{N}$ or $\mathrm{T}$ clades ( $<85 \%$ among). This outcome provides some additional impetus for suggesting the functionally pathogenic $(\mathrm{P})$ clade as a separate genus. However, there is overlap between the $\mathrm{N}$ and T clade $18 \mathrm{~S} \%$ identity measures; and, ITS region data fail to show any such \% identity gap among any of the major/ functional clades.

From the expanded perspective provided by our extensive sampling, it still appears that only one pathogenic species of Labyrinthula, L. zosterae (represented here by haplotypes $1-2$, species A), currently inhabits $Z$. marina beds of the greater north Atlantic and northeast Pacific. Despite the potential to see Labyrinthula-driven selection-based differences among these two regions, the results of our cross-infection experiments show that modern L. zosterae appear equally pathogenic (90-100\%) to plants on both sides of North America. Data on virulence, however, was less clear, showing significant variability within and among experiments and regions. This could be due to any number of factors (e.g., differing plant genetics or condition within and among experiments, or changing pathogen condition over time). However, this species can be present in both green and lesioned leaves, and may modulate host immunity (Brakel et al. 2014). Additionally, our cross-host infection experiments indicate at least the possibility for some
Labyrinthula, such as our isolate $8 \mathrm{~b}$ (haplotype 8 , species E), to become novel pathogens (e.g., in $Z$. marina or $P$. oceanica beds), though $8 \mathrm{~b}$ 's reduced virulence on species like $Z$. marina (this study) might equally argue against it causing epidemics as such an invasive. Regardless, $8 \mathrm{~b}$ is highly pathogenic in all cross-infection challenges put to it (this study; Garcias-Bonet et al. 2011).

At this early point in both ecological and sequence discovery among the Labyrinthula, we provide an additional or enhanced means of delimiting species for the group. In general, our results suggest at least five species of seagrass-pathogenic Labyrinthula, and perhaps ten or more non-pathogenic Labyrinthula from seagrasses and detrital mangrove leaves. We also caution that whether reservoirs of seagrasspathogenic Labyrinthula exist on other substrates (a topic of our ongoing research) has not been well addressed here, especially considering that much of our sampling effort was focused on just two seagrass hosts, Z. marina and T. testudinum, and mangrove leaves. And, although Muehlstein et al. (1988) did not find seagrass-pathogenic morphotypes on local macroalgae, Labyrinthula were originally described from, commonly reported from, and even found to be pathogenic on marine algal macrophytes (Cienkowski 1867; Pokorny 1967; Raghukumar 1986).

Labyrinthula zosterae, perhaps the best-studied species, has been considered an opportunistic pathogen on eelgrass, as it is common among host plants (found in both green and lesioned leaves), and only causes larger die-offs under circumstances of host stress or compromised host immunity (Burge et al. 2013). As such, putatively pathogenic Labyrinthula types might exist as relatively quiescent biotrophs until they reach a certain density, or a threshold-level of damage is reached, thereby triggering host cell death in advance of more aggressive growth as necrotrophs (e.g., Schmid-Hempel and Frank 2007; Leggett et al. 2012). In addition, the fact that Labyrinthula can also be cultured on a variety of media including bacteria and various eukaryotic microbes (Porter 1990), with some ability to infect via waterborne transmission (this study), suggests that they have the ability to dwell on other substrates in nature, at least temporarily. Further, pathogens subject to selective pressures outside a host (e.g., facultative or environmental pathogens) can retain "virulence factors" if they are traits critical to survival and adaptation on non-host-substrates (Casadevall and Pirofski 2007; Morris et al. 2009; Brown et al. 2012). The later reflects a gradual turn from approaches focused mainly on target hosts (e.g., humans, or key crops) in terms of a pathogen's evolution, but having some understanding at a broader level should help focus studies hoping to elucidate mechanisms of virulence between Labyrinthula and seagrasses. Though our molecular analyses and experimental assays distinctly separate seagrass-pathogenic and non-pathogenic species of Labyrinthula, we cannot determine definitively if these pathogens are facultative or obligate parasites without 
additional sampling and experiments to confirm if these haplotypes are also ubiquitous in the environment, capable of surviving without a living host-substrate, and/or able to also reproduce as saprobes.

\section{Conclusions}

Many seagrasses form large, monospecific and even monoclonal beds, a situation that can predispose them to densitydependent aspects of infectious diseases (Bowles and Bell 2004; Bull et al. 2012), and eelgrass can harbor large seasonal reservoirs of Labyrinthula (Bockelmann et al. 2013). Yet, it is also increasingly evident that host-pathogenenvironment interactions can be inherently complex, even for a single host-species system, with differing host and pathogen responses to abiotic factors (and other potentially nonlinear results from integrating two biological systems) confounding predictions for emerging infectious diseases as climate warming and other environmental stressors (e.g., intensive development along coastal ecosystems) persist (Lafferty and Holt 2003; Plowright et al. 2008; Woolhouse 2011; Rohr et al. 2013). For example, Olsen et al. (2015) provide evidence of warmer waters $\left(>28^{\circ} \mathrm{C}\right)$ as refugia from Mediterranean Labyrinthula infections in Posidonia oceanica, an outcome supported by the metabolic theory of ecology (Rohr et al. 2013). It has also been demonstrated recently that the effects of multi-stress exposure (varying temperature, salinity and sediment sulfide levels) on the interaction of Labyrinthula isolate 8b (haplotype 8 , species E) and T. testudinum strongly influence pathogen viability and virulence (Bishop 2013). Furthermore, seagrasses are a diverse, paraphyletic group, reflected in their having re-invaded the ocean realm at least three times (Les et al. 1997), making it that much more difficult to make generalizations.

The genetic, host-geographic and functional perspective presented here should help assist future investigations of seagrass wasting disease by providing ecological and evolutionary context for a working definition of species-level delimitation within the genus. That pathogenic Labyrinthula are ubiquitous has been known for decades, as has their proliferation in some host-stress situations, with the more recent outbreaks having been relatively restricted despite advancing climate change and other anthropogenic influences since the 1930s. Still, seagrasses continue to decline, making it reasonable to hypothesize that Labyrinthula may be playing a role, perhaps as a universal tipping-point mechanism for stressed systems. Future studies embracing comparative hostindependent and -dependent characterizations of the various pathogenic Labyrinthula species should aid in identifying any common etiologic mechanisms that lead to more aggressive infection events, and/or more subtle but chronic situations.
Acknowledgments We are indebted to the numerous colleagues, both locally and abroad, that so graciously provided samples and time for this project, especially C. Tanner and A. Schwarzschild for providing many of the Z. marina shoots for our assays. We further thank the S. Palumbi lab/ PISCO Summer Working Group for providing the inexpensive DNA prep protocol, K. Baya for assistance with primers, and B. Axsmith for generous access to his microscopes. K. Lohan kindly provided helpful comments on an earlier draft of this manuscript; this work also benefitted from the comments of two reviewers. Although the majority of this project was produced pro bono publico, partial funding was provided by: Biology Department, University South Alabama (to DLM); Sea Doc Society through the Karen C. Drayer Wildlife Health Center, School of Veterinary Medicine, University of California, Davis (to DLM, SWE, JKG, AAB); Coastal Biology Program, University of North Florida, with $R / V$ Bellows ship-time - Florida Institute of Oceanography (to CR).

Open Access This article is distributed under the terms of the Creative Commons Attribution 4.0 International License (http:// creativecommons.org/licenses/by/4.0/), which permits unrestricted use, distribution, and reproduction in any medium, provided you give appropriate credit to the original author(s) and the source, provide a link to the Creative Commons license, and indicate if changes were made.

\section{References}

Adl, S.M., A.G.B. Simpson, M.A. Farmer, R.A. Andersen, O.R. Anderson, J.R. Barta, S.S. Bowser, G. Brugerolle, R.A. Fensome, S. Fredericq, T.Y. James, S. Karpov, P. Kugrens, J. Krug, C.E. Lane, L.A. Lewis, J. Lodge, D.H. Lynn, D.G. Mann, R.M. McCourt, L. Mendoza, Ø. Moestrup, S.E. Mozley-Standridge, T.A. Nerad, C.A. Shearer, A.V. Smirnov, F.W. Spiegel, and M.F.J.R. Taylor. 2005. The new higher-level classification of eukaryotes with emphasis on the taxonomy of protists. Journal of Eukaryotic Microbiology 52: 399-451. doi:10.1111/j.1550-7408.2005.00053.x.

Adl, S.M., B.S. Leander, A.G.B. Simpson, J.M. Archibald, O.R. Anderson, D. Bass, S.S. Bowser, G. Brugerolle, M.A. Farmer, S. Karpov, M. Kolisko, C.E. Lane, D.J. Lodge, D.G. Mann, R. Meisterfeld, L. Mendoza, Ø. Moestrup, S.E. Mozley-Standridge, A.V. Smirnov, and F.W. Spiegel. 2007. Diversity, nomenclature, and taxonomy of protists. Systematic Biology 56: 684-689. doi:10. 1080/10635150701494127.

Amon, J.P., and F.O. Perkins. 1968. Structure of Labyrinthula sp. zoospores. Journal of Protozoology 15: 543-546.

Anderson, O.R., and T. Cavalier-Smith. 2012. Ultrastructure of Diplophrys parva, a new small freshwater species, and a revised analysis of Labyrinthulea (Heterokonta). Acta Protozoologica 51: 291-304. doi:10.4467/16890027AP.12.023.0783.

Anne, C. 2006. Choosing the right molecular genetic markers for studying biodiversity: from molecular evolution to practical aspects. Genetica 127(1-3): 101-120.

Apakupakul, K., M.E. Siddall, and E.M. Burreson. 1999. Higher level relationships of leeches (Annelida: Clitellata: Euhirudinea) based on morphology and gene sequences. Molecular Phylogenetics and Evolution 12(3): 350-359. doi: 10.1006/mpev.1999.0639.

Armiger, L.C. 1964. An occurrence of Labyrinthula in New Zealand Zostera. New Zealand Journal of Botany 2(1): 3-9.

Arnaud-Haond, S., C.M. Duarte, E. Diaz-Almela, N. Marbà, T. Sintes, and E.A. Serrão. 2012. Implications of extreme life span in clonal organisms: millenary clones in meadows of the threatened seagrass Posidonia oceanica. PLoS ONE 7(2): e30454. 
Beakes, G.W., D. Honda, and M. Thines. 2014. Systematics of the Straminipila: Labyrinthulomycota, Hyphochytriomycota and Oomycota. In: Systematics and evolution, 2nd Edition. The Mycota VII Part A, eds. McLaughlin, D.J., and J. Spatafora, 39-97. Berlin Heidelberg: Springer-Verlag. doi:10.1007/978-3642-55318-9 3

Ben-Dov, E., E. Kramarsky-Winter, and A. Kushmaro. 2009. An in situ method for cultivating microorganisms using a double encapsulation technique. FEMS Microbiology Ecology 68: 363-371. doi:10.1111/ j.1574-6941.2009.00682.x.

Bergmann, N., B. Fricke, M.C. Schmidt, V. Tams, K. Beining, H. Schwitte, A.A. Boettcher, D.L. Martin, A.C. Bockelmann, T.B.H. Reusch, and G. Rauch. 2011. A quantitative real-time polymerase chain reaction assay for the seagrass pathogen Labyrinthula zosterae. Molecular Ecology Resources 11: 1076-1081. doi:10. 1111/j.1755-0998.2011.03051.x.

Bigelow, D.M., and M.W. Olsen. 2004. Investigations of the host range of Labyrinthula terrestris, a new turfgrass pathogen. Turfgrass, landscape and urban IPM research summary. Tucson: College of Agriculture and Life Sciences, University of Arizona.

Bigelow, D.M., M.W. Olsen, and R.L. Gilbertson. 2005. Labyrinthula terrestris sp. nov., a new pathogen of turf grass. Mycologia 97: 185-190.

Bishop, N. 2013. The effects of multiple abiotic stressors on the susceptibility of the seagrass Thalassia testudinum to Labyrinthula sp., the causative agent of wasting disease. Master's Thesis. College of Arts and Sciences, University of North Florida, Jacksonville, Florida, USA. 96 p.

Bockelmann, A.-C., K. Beining, and T.B.H. Reusch. 2012. Widespread occurrence of endophytic Labyrinthula spp. in northern European eelgrass Zostera marina beds. Marine Ecology Progress Series 445: 109-116. doi:10.3354/meps09398.

Bockelmann, A.-C., V. Tams, J. Ploog, P.R. Schubert, and T.B.H. Reusch. 2013. Quantitative PCR reveals strong spatial and temporal variation of the wasting disease pathogen, Labyrinthula zosterae in northern European eelgrass (Zostera marina) beds. PLoS ONE 8(5): e62169-10. doi:10.1371/journal.pone.0062169.

Boenigk, J., M. Ereshefsky, K. Hoef-Emden, J. Mallet, and D. Bass. 2012. Concepts in protistology: species definitions and boundaries. European Journal of Protistology 48(2): 96-102. doi:10.1016/j. ejop.2011.11.004.

Bowles, J.W., and S.S. Bell. 2004. Simulated herbivory and the dynamics of disease in Thalassia testudinun. Marine Ecology Progress Series 283: $127-132$.

Brakel, J., F.J. Werner, V. Tams, T.B.H. Reusch, and A.-C. Bockelmann. 2014. Current European Labyrinthula zosterae are not virulent and modulate seagrass (Zostera marina) defense gene expression. PLoS ONE 9(4): e92448. doi:10.1371/journal.pone.0092448.

Brown, S.P., D.M. Cornforth, and N. Mideo. 2012. Evolution of virulence in opportunistic pathogens: generalism, plasticity, and control. Trends in Microbiology 20: 336-342. doi:10. 1016/j.tim.2012.04.005.

Bull, J.C., E.J. Kenyon, and K.J. Cook. 2012. Wasting disease regulates long-term population dynamics in a threatened seagrass. Oecologia 169: 135-142. doi:10.1007/s00442-011-2187-6.

Burge, C.A., C.J.S. Kim, J.M. Lyles, and C.D. Harvell. 2013. Special issue oceans and humans health: the ecology of marine opportunists. Microbial Ecology 65(4): 869-879. doi:10.1007/s00248-013-0190-7.

Burge, C.A., C.M. Eakin, C.S. Friedman, B. Froelich, P.K. Hershberger, E.E. Hofmann, L.E. Petes, K.C. Prager, E. Weil, B.L. Willis, S.E. Ford, and C.D. Harvell. 2014. Climate change influences on marine infectious diseases: implications for management and society. Marine Science 6: 249-277. doi:10.1146/annurev-marine-010213-135029.

Carstens, B.C., T.A. Pelletier, N.M. Reid, and J.D. Satler. 2013. How to fail at species delimitation. Molecular Ecology 22(17): 4369-4383. doi:10.1111/mec.12413.
Casadevall, A., and L.-A. Pirofski. 2003. The damage-response framework of microbial pathogenesis. Nature Reviews Microbiology 1(1): 17-24. doi:10.1038/nrmicro732.

Casadevall, A., and L.-A. Pirofski. 2007. Accidental virulence, cryptic pathogenesis, martians, lost hosts, and the pathogenicity of environmental microbes. Eukaryotic Cell 6(12): 2169-2174. doi:10.1128/ EC.00308-07.

Castresana, J. 2000. Selection of conserved blocks from multiple alignments for their use in phylogenetic analysis. Molecular Biology and Evolution 17: 540-552.

Cienkowski, L.V. 1867. Ueber den Bau und die Entwickelung der Labyrinthuleen. Archiv für Mikroskopische Anatomie 3(1): 274 310. doi:10.1007/BF02960460.

Collado-Mercado, E., J.C. Radway, and J.L. Collier. 2010. Novel uncultivated labyrinthulomycetes revealed by $18 \mathrm{~S}$ rDNA sequences from seawater and sediment samples. Aquatic Microbial Ecology 58: 215-228. doi:10.3354/ame01361.

Craven, K.D., P.D. Peterson, D.E. Windham, T.K. Mitchell, and S.B. Martin. 2005. Molecular identification of the turf grass rapid blight pathogen. Mycologia 97(1): 160-166. doi:10.3852/mycologia.97.1.160.

Darriba, D., G.L. Taboada, R. Doallo, and D. Posada. 2012. jModelTest 2: more models, new heuristics and parallel computing. Nature Methods 9(8): 772. doi:10.1038/nmeth.2109.

Daszak, P., A.A. Cunningham, and A.D. Hyatt. 2000. Emerging infectious diseases of wildlife - threats to biodiversity and human health. Science 287: 443-449.

de Queiroz, K. 2007. Species concepts and species delimitation. Systematic Biology 56(6): 879-886. doi:10.1080/ 10635150701701083.

Dick, M.W. 2001. Straminipilous fungi: systematics of the peronosporomycetes including accounts of the marine straminipilous protists, the plasmodiophorids and similar organisms. Dordrecht: Kluwer Academic Publishers.

Dobson, A., and J. Foufopoulos. 2001. Emerging infectious pathogens of wildlife. Philosophical Transactions of the Royal Society B 356: 1001-1012. doi:10.1098/rstb.2001.0900.

Doney, S.C., M. Ruckelshaus, J.E. Duffy, J.P. Barry, F. Chan, C.A. English, H.M. Galindo, J.M. Grebmeier, A.B. Hollowed, N. Knowlton, J. Polovina, N.N. Rabablais, W.J. Sydeman, and L.D. Talley. 2012. Climate change impacts on marine ecosystems. Annual Review of Marine Science 4: 11-37. doi:10.1146/annurevmarine-041911-111611

Douhan, G.W., M.W. Olsen, A. Herrell, C. Winder, F. Wong, and K. Entwistle. 2009. Genetic diversity of Labyrinthula terrestris, a newly emergent plant pathogen, and the discovery of new Labyrinthulid organisms. Mycological Research 113: 1192-1199. doi:10.1016/j. mycres.2009.08.002.

Duarte, C.M., W.C. Dennison, R.J.W. Orth, and T.J.B. Carruthers 2008. The charisma of coastal ecosystems: addressing the imbalance. Estuaries and Coasts 31(2): 233-238. doi:10.1007/ s12237-008-9038-7.

Duarte, C.M., T. Sintes, and N. Marbà. 2013. Assessing the $\mathrm{CO}_{2}$ capture potential of seagrass restoration projects. Edited by Shiqiang Wan. Journal of Applied Ecology 50: 1341-1349. doi:10.1111/13652664.12155.

Dyková, I., I. Fiala, H. Dvořáková, and H. Pecková. 2008. Living together: the marine amoeba Thecamoeba hilla Schaeffer, 1926 and its endosymbiont Labyrinthula sp. European Journal of Protistology 44: 308-316. doi:10.1016/j.ejop.2008.04.001.

Epstein, P. 2010. The ecology of climate change and infectious diseases: comment. Ecology 91(3): 925-928. discussion 928-9.

FaBox online services: http://users-birc.au.dk/biopv/php/fabox/ index.php.

Garcias-Bonet, N., T.D. Sherman, C.M. Duarte, and N. Marbà. 2011. Distribution and pathogenicity of the protist Labyrinthula sp. In 
western Mediterranean seagrass meadows. Estuaries and Coasts 34: 1161-1168. doi:10.1007/s12237-011-9416-4.

Guindon, S., J.-F. Dufayard, V. Lefort, M. Anisimova, W. Hordijk, and O. Gascuel. 2010. New algorithms and methods to estimate maximumlikelihood phylogenies: assessing the performance of PhyML 3.0. Systematic Biology 59(3): 307-321. doi:10.1093/sysbio/syq010.

Harvell, C.D., K. Kim, J.M. Burkholder, R.R. Colwell, P.R. Epstein, D.J. Grimes, E.E. Hofmann, E.K. Lipp, A.D. Osterhaus, R.M. Overstreet, J.W. Porter, G.W. Smith, and G.R. Vasta. 1999. Emerging marine diseases-climate links and anthropogenic factors. Science 285: 1505-1510. doi:10. 1126/science. 285.5433 .1505

Harvell, C.D., C.E. Mitchell, J.R. Ward, S. Altizer, A.P. Dobson, R.S. Ostfeld, and M.D. Samuel. 2002. Climate warming and disease risks for terrestrial and marine biota. Science 296: 2158-2162. doi:10. 1126/science. 1063699

Heger, T.J., V.P. Edgcomb, E. Kim, J. Lukeš, B.S. Leander, and N. Yubuki. 2014. A resurgence in field research is essential to better understand the diversity, ecology, and evolution of microbial eukaryotes. Journal of Eukaryotic Microbiology 61: 214-223. doi: 10.1111/jeu.12095.

Hewson, I., J.B. Button, B.M. Gudenkauf, B. Miner, A.L. Newton, J.K. Gaydos, J. Wynne, C.L. Groves, G. Hendler, M. Murray, S. Fradkin, M. Breitbart, E. Fahsbender, K.D. Lafferty, A.M. Kilpatrick, C.M. Miner, P. Raimondi, L. Lahner, C.S. Friedman, S. Daniels, M. Haulena, J. Marliave, C.A. Burge, M.E. Eisenlord, and C.D. Harvell. 2014. Densovirus associated with sea-star wasting disease and mass mortality. Proceedings of the National Academy of Sciences of the United States of America 111(48): 17278-17283. doi:10.1073/pnas.1416625111.

Honda, D., T. Yokochi, T. Nakahara, S. Raghukumar, A. Nakagiri, K. Schaumann, and T. Higashihara. 1999. Molecular phylogeny of labyrinthulids and thraustochytrids based on the sequencing of 18S ribosomal RNA gene. Journal of Eukaryotic Microbiology 46(6): 637-647.

Jackson, J.B. 2008. Ecological extinction and evolution in the brave new ocean. Proceedings of the National Academy of Sciences of the United States of America 105(Supplement 1): 11458-11465. doi: 10.1073/pnas.0802812105.

Jackson, J.B. 2010. The future of the oceans past. Philosophical Transactions of the Royal Society of London, Series B 365(1558): 3765-3778. doi:10.1098/rstb.2010.0278.

Kenworthy, W.J., S. Wyllie-Echeverria, R.G. Coles, G. Pergent, and C. Pergent-Martini. 2006. Seagrass conservation biology: an interdisciplinary science for protection of the seagrass biome. In: Seagrasses: Biology, Ecology and Conservation, eds. Larkum, A.W.D., R.J. Orth, and C.M. Duarte, 595-623. Netherlands: Springer.

Lafferty, K.D. 2009. The ecology of climate change and infectious diseases. Ecology 90(4): 888-900.

Lafferty, K.D., and R.D. Holt. 2003. How should environmental stress affect the population dynamics of disease? Ecology Letters 6(7): 654-664. doi:10.1046/j.1461-0248.2003.00480.x.

Lafferty, K.D., J.W. Porter, and S.E. Ford. 2004. Are diseases increasing in the ocean? Annual Review of Ecology, Evolution, and Systematics 35: 31-54. doi:10.1146/annurev.ecolsys.35.021103.105704.

Leander, C.A., and D. Porter. 2001. The Labyrinthulomycota is comprised of three distinct lineages. Mycologia 93: 459-464.

Leggett, H.C., C.K. Cornwallis, and S.A. West. 2012. Mechanisms of pathogenesis, infective dose and virulence in human parasites. PLoS Pathogens 8(2): e1002512. doi:10.1371/journal. ppat. 1002512 .

Les, D.H., M.A. Cleland, and M. Waycott. 1997. Phylogenetic studies in Alismatidae, II: evolution of marine angiosperms (seagrasses) and hydrophily. Systematic Botany 22: 443-463.
Medlin, L., H.J. Elwood, S. Stickel, and M.L. Sogin. 1988. The characterization of enzymatically amplified eukaryotic 16S-like rRNAcoding regions. Gene 71(2): 491-499.

Morris, C.E., M. Bardin, L.L. Kinkel, B. Moury, P.C. Nicot, and D.C. Sands. 2009. Expanding the paradigms of plant pathogen life history and evolution of parasitic fitness beyond agricultural boundaries. PLoS Pathogens 5(12): e1000693. doi:10.1371/ journal.ppat.1000693.

Muehlstein, L.K., D. Porter, and F.T. Short. 1988. Labyrinthula sp., a marine slime mold producing the symptoms of wasting disease in eelgrass, Zostera marina. Marine Biology 99: 465-472. doi:10. 1007/BF00392553.

Muehlstein, L.K., D. Porter, and F.T. Short. 1991. Labyrinthula zosterae sp. nov., the causative agent of wasting disease of eelgrass, Zostera marina. Mycologia 83: 180-191.

Olive, L.S. 1975. The mycetozoans. New York: Academic.

Olsen, Y.S., M. Potouroglou, N. Garcias-Bonet, and C.M. Duarte. 2015. Warming reduces pathogen pressure on a climate-vulnerable seagrass species. Estuaries and Coasts 38: 659-667. doi:10.1007/ s12237-014-9847-9.

Orth, R.J., T.J.B. Carruthers, W.C. Dennison, C.M. Duarte, J.W. Fourqurean, K.L. Heck Jr., A.R. Hughes, G.A. Kendrick, W.J. Kenworthy, S. Olyarnik, F.T. Short, M. Waycott, and S.L. Williams. 2006. A global crisis for seagrass ecosystems. BioScience 56: 987-996. doi:10.1641/0006-3568(2006) 56[987:AGCFSE]2.0.CO;2.

Padial, J.M., A. Miralles, I. De la Riva, and M. Vences. 2010. Review: the integrative future of taxonomy. Frontiers in Zoology 7: 1-14.

Pawlowski, J., S. Audic, S. Adl, D. Bass, L. Belbahri, C. Berney, S.S. Bowser, I. Cepicka, J. Decelle, M. Dunthorn, A.M. Fiore-Donno, G.H. Gile, M. Holzmann, R. Jahn, M. Jirku, P.J. Keeling, M. Kostka, A. Kudryavtsev, E. Lara, J. Lukes, D.G. Mann, E.A.D. Mitchell, F. Nitsche, M. Romeralo, G.W. Saunders, A.G.B. Simpson, A.V. Smirnov, J.L. Spouge, R.F. Stern, T. Stoeck, J. Zimmermann, D. Schindel, and C. de Vargas. 2012. CBOL protist working group: barcoding eukaryotic richness beyond the animal, plant, and fungal kingdoms. PLoS Biology 10(11): e1001419. doi: 10.1371/journal.pbio.1001419.

Plowright, R.K., S.H. Sokolow, M.E. Gorman, P. Daszak, and J.E. Foley. 2008. Causal inference in disease ecology: investigating ecological drivers of disease emergence. Frontiers in Ecology and the Environment 6(8): 420-429. doi:10.1890/070086.

Pokorny, K.S. 1967. Labyrinthula. Journal of Protozoology 14: 697-708. doi:10.1111/j.1550-7408.1967.tb02065.x.

Porter, D. 1990. Phylum Labyrinthulomycota. In Handbook of Protoctista, ed. L. Margulis, J.O. Corliss, M. Meklonian, and D.J. Chapman, 388-398. Boston: Jones and Bartlett Publishers.

Raghukumar, C. 1986. Fungal parasites of the marine green algae, Cladophora and Rhizoclonium. Botanica Marina 29: 289-297. doi:10.1515/botm.1986.29.4.289.

Raghukumar, S., and V.S. Damare. 2011. Increasing evidence for the important role of Labyrinthulomycetes in marine ecosystems. Botanica Marina 54(1): 1-10. doi:10.1515/bot.2011.008.

Renn, C.E. 1936. The wasting disease of zostera marina. I. A phytological investigation of the diseased plant. Biological Bulletin 70: 148-158. doi: $10.2307 / 1537320$.

Robideau, G.P., A.W. de Cock, M.D. Coffey, H. Voglmayr, H. Brouwer, K. Bala, D.W. Chitty, N. Désaulniers, Q.A. Eggertson, C.M.M. Gachon, C.-H. Hu, F.C. Küpper, T.L. Rintoul, E. Sarhan, E.C.P. Verstappen, Y. Zhang, P.J.M. Bonants, J.B. Ristaino, and C.A. Lévesque. 2011. DNA barcoding of oomycetes with cytochrome c oxidase subunit I and internal transcribed spacer. Molecular Ecology Resources 11: 1002-1011. doi:10.1111/j.1755-0998.2011.03041.x.

Rohr, J.R., T.R. Raffel, A.R. Blaustein, P.T.J. Johnson, S.H. Paull, and S. Young. 2013. Using physiology to understand climate-driven 
changes in disease and their implications for conservation. Conservation Physiology 1: 1-15. doi:10.1093/conphys/cot022.

Schmid-Hempel, P., and S.A. Frank. 2007. Pathogenesis, virulence, and infective dose. PLoS Pathogens 3(10): e147-2. doi:10.1371/journal. ppat.0030147.

Schoch, C.L., K.A. Seifert, S. Huhndorf, V. Robert, J.L. Spouge, C.A. Levesque, W. Chen, and Fungal Barcoding Consortium. 2012. Nuclear ribosomal internal transcribed spacer (ITS) region as a universal DNA barcode marker for Fungi. Proceedings of the National Academy of Sciences of the United States of America 109(16): 6241-6246. doi:10.1073/pnas.1117018109.

Short, F.T., and S. Wyllie-Echeverria. 1996. Natural and human-induced disturbance of seagrasses. Environmental Conservation 23(1): 1727. doi:10.1017/S0376892900038212.

Short, F., T. Carruthers, W. Dennison, and M. Waycott. 2007. Global seagrass distribution and diversity: a bioregional model. Journal of Experimental Marine Biology and Ecology 350: 3-20. doi:10.1016/ j.jembe.2007.06.012.

Spalding, M.D., H.E. Fox, G.R. Allen, N. Davidson, Z.A. Ferdaña, M. Finlayson, B.S. Halpern, M.A. Jorge, A. Lombana, S.A. Lourie, K.D. Martin, E. McManus, J. Molnar, C.A. Recchia, and J. Robertson. 2007. Marine ecoregions of the world: a bioregionalization of coastal and shelf areas. BioScience 57(7): 573-583. doi:10.1641/B570707.

Steele, L., M. Caldwell, A.A. Boettcher, and T. Arnold. 2005. Seagrass-pathogen interactions: "pseudo-induction" of turtlegrass phenolics near wasting disease lesions. Marine Ecology Progress Series 303: 123-131.

Sullivan, B.K., T.D. Sherman, V.S. Damare, O. Lilje, and F.H. Gleason. 2013. Potential roles of Labyrinthula spp. in global seagrass population declines. Fungal Ecology 6(5): 328-338. doi:10.1016/j. funeco.2013.06.004.

Tamura, K., G. Stecher, D. Peterson, A. Filipski, and S. Kumar. 2013. MEGA6: molecular evolutionary genetics analysis version 6.0. Molecular Biology and Evolution 30: 2725-2729. doi:10.1093/ molbev/mst197.
Tsui, C.K.M., W. Marshall, R. Yokoyama, D. Honda, J.C. Lippmeier, K.D. Craven, P.D. Peterson, and M.L. Berbee. 2009. Labyrinthulomycetes phylogeny and its implications for the evolutionary loss of chloroplasts and gain of ectoplasmic gliding. Molecular Phylogenetics and Evolution 50: 129-140. doi:10.1016/ j.ympev.2008.09.027.

Vergeer, L.H.T., and C. den Hartog. 1994. Omnipresence of Labyrinthulaceae in seagrasses. Aquatic Botany 48: 1-20. doi:10. 1016/0304-3770(94)90070-1.

Ward, J.R., and K.D. Lafferty. 2004. The elusive baseline of marine disease: are diseases in ocean ecosystems increasing? PLoS Biology 2(4): e120-e126. doi:10.1371/journal.pbio.0020120.

Watson, S.W. 1957. Cultural and cytological studies on species of Labyrinthula. Ph.D. Thesis. 165 pp. The University of Wisconsin: Madison.

Waycott, M., C.M. Duarte, T.J.B. Carruthers, R.J. Orth, W.C. Dennison, S. Olyarnik, A. Calladine, J.W. Fourqurean, K.L. Heck Jr., A.R. Hughes, G.A. Kendrick, W.J. Kenworthy, F.T. Short, and S.L. Williams. 2009. Accelerating loss of seagrasses across the globe threatens coastal ecosystems. Proceedings of the National Academy of Sciences of the United States of America 106: 1237712381. doi:10.1073/pnas.0905620106.

White, T.J., T. Bruns, S. Lee, and J.W. Taylor. 1990. Amplification and direct sequencing of fungal ribosomal RNA genes for phylogenetics. In: PCR Protocols: A Guide to Methods and Applications, eds. Innis, M.A., D.H. Gelfand, J.J. Sninsky, and T.J. White, 315322. Academic Press: San Diego.

Wilson, K. 2009. Climate change and the spread of infectious ideas. Ecology 90: 901-902. doi:10.1890/08-2027.1.

Woolhouse, M. 2011. How to make predictions about future infectious disease risks. Philosophical Transactions of the Royal Society $B$ 366(1573): 2045-2054. doi:10.1098/rstb.2010.0387.

Young, E.L. 1943. Studies on Labyrinthula. The etiologic agent of the wasting disease of eel-grass. American Journal of Botany 30: 586-593.

Zar, J.H. 1984. Biostatistical analysis, 2nd ed. Englewood Cliffs: Prentice-Hall. 